\title{
Exploration of Students' Arguments to Identify Perplexity from Reflective Process on Mathematical Problems
}

\section{Flavia Aurelia Hidajat}

Dr. Candidate in Mathematics Education, Graduate School, Universitas Negeri Malang, Lecturer in Mathematics Education, Graduate School, Universitas Panca Marga Probolinggo, East Java, Indonesia, flaviadorothea@ gmail.com

\section{Cholis Sa'dijah}

Prof., in Mathematics Education, Corresponding author, Graduate School Universitas Negeri Malang, East Java, Indonesia, cholis.sadijah.fmipa@um.ac.id

\section{Sudirman}

Dr., Senior Lecturer in Mathematics Education, Graduate School, Universitas Negeri Malang, East Java, Indonesia, sudirman.fmipa@um.ac.id

\section{Susiswo}

Dr., Senior Lecturer in Mathematics Education, Graduate School, Universitas Negeri Malang, East Java, Indonesia, susiswo.fmipa@um.ac.id

This research is based on an individual case finding, where the response from individuals in answering the mathematical problems is initiated with perplexity to proceed with the new finding by reflecting on the previous experience. This research aimed at contributing practically on the indicators causing a perplexity on students which described the initial process of reflective thinking through students' argument exploration when responding to a problem. This research is a qualitative research with a case study of two students as research subjects. This finding showed that students stated four sequences of Arguments which described perplexity of the students during the interview. This perplexity showed several indicators that were students' unfamiliarity in imagination and creation on nonregular questions; incompatibility of problem-solving strategy owned by someone with the new problem-solving coming from; misunderstanding of students due to incompatibility in students' experience, or the existence of a forgetfulness factor; and the failure in generating new ideas and strategies.

Keywords: exploration, argument, perplexity, reflective, mathematical problems

Citation: Hidajat, F. A., Sa'dijah, C., Sudirman, \& Susiswo. (2019). Exploration of Students' Arguments to Identify Perplexity from Reflective Process on Mathematical Problems. International Journal of Instruction, 12(2), 573-586. https://doi.org/10.29333/iji.2019.12236a 


\section{INTRODUCTION}

Mathematical problem is very important for the development of the mathematical sciences. According to Bell (1978), an individual experiences a problem when someone has the will to solve it but unable to find a way to solve the problem immediately. A problem is often perceived as a challenging question which cannot be solved with a regular procedure or promptly (Posamentier \& Krulik, 2009) and able to stimulate students' thinking (X. Huang \& Lee, 2015). Proulx (2015) confirmed that a good problem can trigger an individual to make an effort in solving the problem. Several studies have reviewed problem-solving such as Muis, Chevrier, \& Singh (2018); Ricks (2011). Muis et al. (2018) stated that a situation from a high curiosity, confusion, or positive perplexity helps the process of cognitive and metacognitive in solving a problem. Meanwhile, Ricks (2011) also suggest that an unsettled condition or curiosity can encourage someone to reflect on the previous experience and force spontaneous ideas to solve the problem. One of the significant materials in problem-solving to encourage or challenge an individual in solving is a plane figure problem-solving.

Plane figure is a field of mathematics often found in daily life and has been studied in some research nowadays. Papadopoulos (2009) studied the process of irregular plane figure area problem-solving on students, where the students reflect, adapt and expand their prior experience to resolve perplexity in determining irregular plane figure area in which they have never learned about the shapes of the figures. In contrary to Papadopoulos (2009), Skoumpourdi \& Mpakopoulou (2011) investigated the process of problem-solving on the introduction of plane figure shape through concrete objects from the daily life to help resolve wrong part of speech of geometric on students of kindergarten. Different from two previous studies, Yanik (2014) investigated the problem-solving process in 44 mathematics teacher candidates in secondary schools, the prospective teachers used the initial knowledge of transformation and geometry translations to overcome the problems of geometry translation. Study results from (Papadopoulos, 2009; Skoumpourdi \& Mpakopoulou, 2011; Yanik, 2014) showed that the reflection process from the previous experience or from daily life helps students to overcome perplexity, misconception, difficulties as well as doubt in understanding the process of plane figure problem-solving. However, they have not described the causing indicator of perplexity, therefore this condition may contribute to many questions from researchers and teachers to identify the students' perplexity which is the initial stage of reflective thinking. Thus, this research intended to explore and identify the causing indicators of students' perplexity in mathematical problem-solving. The problemsolving was performed by the respondents after the research distributed the mathematical problems.

Mathematical problems given by the researchers to students aim to see various students' response in resolving the problems, of course, students give various responses to the problems. Several studies have observed imperative points on the students' response in solving mathematical problems (Eck, 2011; Hallowell, Okamoto, Romo, \& LaJoy, 2015; Wu \& Adams, 2006). (Hallowell et al., 2015) observed students' response from the process of plane figure problem-solving with the assistance of 2-dimension plane 
figure diagram/sketch media, where students have difficulties in responding and solving the plane figure problems through the media. (Yopp, Burroughs, \& Lindaman, 2011) also identify students' responses when solving problems, where students are initially confused and difficult to respond to problems because they misunderstand their experiences so far but they can respond and develop their understanding well after repeated reflection through interviews Wu \& Adams (2006) stated that students' difficulties or other inhibiting factors in responding to the next problem-solving. The process of problem-solving is considered by Eck (2011) as the actual form of students' response result on the problem.

Based on the preliminary study in November 2017, VII grade students of Laboratorium Malang Junior High school Universitas Negeri Malang were given mathematical questions-problems to identify their response. The results showed that 90 students showed perplexity in solving the problem. 12 out of 90 students can improve their perplexity as a new idea invention Pagano \& Roselle (2009) argued that perplexity is a good initial stage in reflective thinking to solve the problem. According to Lassig (2013), someone unconsciously reflects back, synthesizes, and adapts existing experiences to find originality in creativity. However, a perplexity that is not accompanied by a reflection process can make students dissolved in these conditions and finally find an incompatible solution or even stop. This was demonstrated by 78 students in the initial study with similar responses.

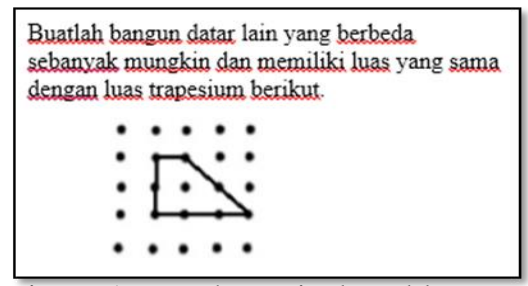

Figure 1a. Mathematical Problems

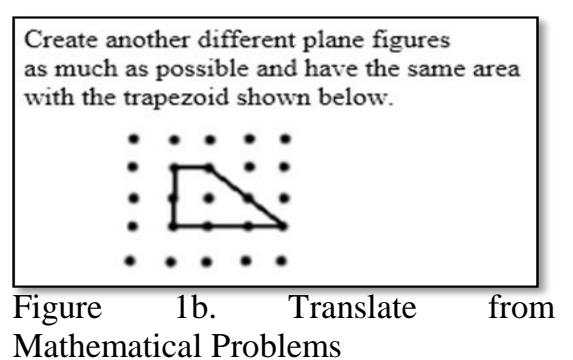

Mathematical Problems

Below is the example of student's response on plane figure problem.

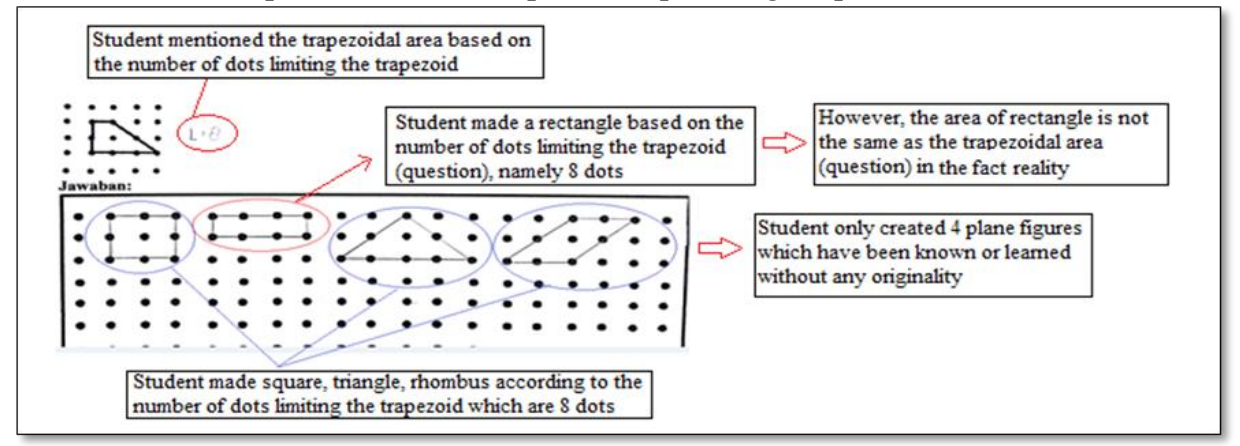

Figure 2

The Student's Response on Plane Figure Problem 
In figure 2, the student determines the area of the trapezoid by calculating the number of points that limit the trapezoid so that the area of the trapezoid is 8 units. The next step is that students create four plane figures with an area equal to the area of the trapezoid in accordance with the number of points that limit the trapezoid (question), including square, rectangular, triangular, and long distance. Students do not reflect back on the previous experience of the basic concept of the plane figure, so they considered the area of the trapezoid and the area of the four plane figures was the number of points that limit the plane figure. Based on the results of the student's work on the construct of square, triangle, and parallel angle, these three plane figures coincidentally have an area equal to the area of the trapezoid, where the actual area of the three figures was in sequence was

side $\times$ side $=2 \times 2=4$ units; $\frac{1}{2} \times$ base $\times$ height $=\frac{1}{2} \times 4 \times 2=4$ units; dan base $\times$ height $=4$ units. However, the area of rectangle showed different results from the trapezoid area because based on the actual rectangle area concept, "rectangle area =

length $\times$ width", which is $3 \times 1=3$ units and trapezoid area $=\frac{1}{2} \times$ (upper side + lower side) $\times$ height $=\frac{1}{2} \times(1+3) \times 2=4$ units.

Based on this information, students experienced perplexity on the given problems. This can be seen that students considered the point as side length, students determined the plane figure area by using a fundamental plane figure circumference concept which is obtained by calculating the length of all sides which circumference the figure, and the students did not reflect on the results of their work. It is very important that we know the causing indicators of the perplexity experienced by students when responding to problems, to provide practical knowledge to educators and researchers so that educators can utilize this knowledge as a reflective material to plan good learning strategies for students in responding to problems and researchers can further develop knowledge about indicators of perplexity in students as the initial process of reflective thinking in response to problems.

Therefore, this research aimed at contributing to the theoretical knowledge on the indicators of perplexity which describe the initial process of reflective thinking incidence in responding to a problem.

\section{METHOD}

\section{Design}

This qualitative research is a case study. It is called as a case study research because the researcher conducted an in-depth study and investigation on the background of a social unit, such as individual, group, and others (Azwar, 2017). This research describes the indicator of perplexity experienced by the students in responding to mathematical problems. 


\section{Material}

The data from this research were students' arguments in the form of written and spoken obtained by utilizing test instruments from mathematical problems on plane figure and interview. Mathematical problems about plane figures in this study include challenging questions that are irregular and open-ended (see Figure 1.a). The data from the interview aimed to validate the data. The data validation process for this research used member checking, where the researcher acted as the subject of the description from the stated arguments by conducting interviews (Creswell, 2015).

\section{Research Subjects}

Subjects from this research were two students. These two students were from Laboratorium Universitas Negeri Malang Junior High School and Surya Buana Malang Islamic Junior High School. The selection of the research subjects included several criteria which are (1) students from junior high school ranged from 12 to 13 years old, (2) students were capable to deal with the results of their thinking in spoken and written form, (3) students have obtained the plane figure material, and (4) students have perplexity in responding to the mathematical problems.

\section{Procedure}

This research procedure began by selecting 127 Junior High School students aged 13 to 14 years old from several schools who were able to communicate the results of their thinking in spoken and written form. The selection was based on a teacher's recommendation from each school. The selected students (127 students) were given mathematical problems on plane figures. Of the 127, 80 students were confused when responding to the chosen problems. Furthermore, two out of 80 students were chosen because 80 other students had similar arguments/responses when responding to the problems. Both students were interviewed on the reasons of perplexity incidence they experienced in responding to the problems. The interview aimed at validating the existing data and the data were then analyzed.

\section{Data Collection Method}

The data were collected from tests, interview, and observation. The test aimed at exploring the students' argument in responding to mathematical problems. When students took the test, the students' expressions and behaviors were observed in detail and carefully with the help of video and direct observation. In addition, in-depth interviews were conducted related to students' arguments when responding to mathematical problems. Test, observations, and interviews were conducted to determine the research subjects based on the students' criteria who encountered perplexity in resolving mathematical problems. The results from test, observation, and in-depth interview were then analyzed.

\section{Data Analysis}

The good and valid data were used to describe the causing indicators of students' perplexity in responding to the mathematical problem. The analysis process in this research was conducted in the stages which are (1) the data reduction with the focus on 
the selection of required main matters and deleted unnecessary matters; (2) the data presentation was the stage of analysis and data grouping which have been reduced into four indicators from the students' perplexity in responding to mathematical problems; (3) the conclusion on the results of findings and data presentation.

\section{FINDINGS}

\section{First Subject}

The first subject experienced a perplexity in responding to mathematical problems. The perplexity experienced by students is shown through 4 sequences of arguments from students when solving problems. Students put forward a sequence of arguments before they worked on the problem. The sequence of arguments was in the form of several questions that students asked about information in the problem because they have never known such a problem and were doubtful about determining a problem-solving plan. Here are some questions from students which show that students experience perplexity on problems.

\section{S1 : Miss, what does this mean? ${ }^{(\mathrm{I}, \mathrm{II})}$}

Based on this question, the researcher asked the student as followings.

P : Why?

S1 : Hmmm... Do you think the question provides an unknown length of each side? ${ }^{\text {(I, II) }}$

$\mathrm{P} \quad$ : How the side is unknown? Do you think the question is wrong?

S1 : Hmmm... let me give an example, the line segment from one point to another is 4, thus, first I will find the area of this trapezoid

S1 : But, what is the trapezoidal area formulation? ${ }^{(\text {III) }}$

$\mathrm{P} \quad$ : Have you not been taught about the trapezoid area?

S1 : Yes, I have, Miss. But I forgot the trapezoidal area formulation. ${ }^{\text {(III) }}$

S1 : Well ... I have got an idea. (a) I try to divide the trapezoid figure into three square units and 2 triangular units; (b) I calculate each area of the square unit and triangular unit; next (c) I calculated each area from the square units and triangular units. So the trapezoid are is 64 units.

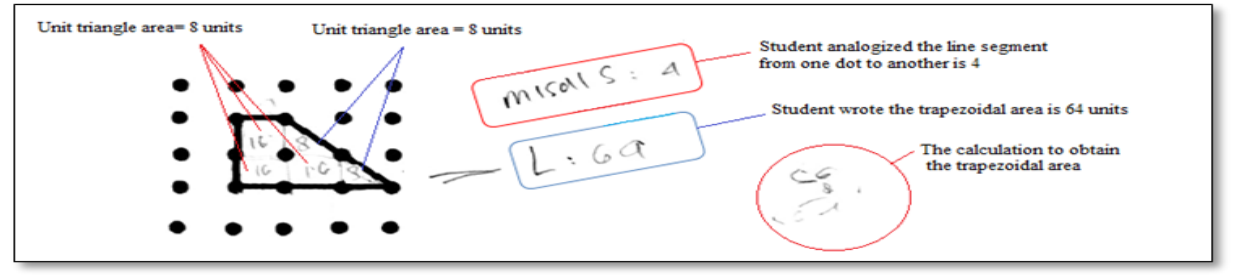

Figure 3

The Results of the First Students' Work in Performing Interview

Based on the short interview in initiating the problem-solving, students were asked to fill the problem worksheet according to the description as in Figure 3. The students then asked the researcher again since they experienced misconception on the experience they have to overcome the problems that they faced. In this case, students stated several 
arguments showing the perplexity in responding to the problems. The perplexity was shown on several questions and arguments related to the plane figure concept.

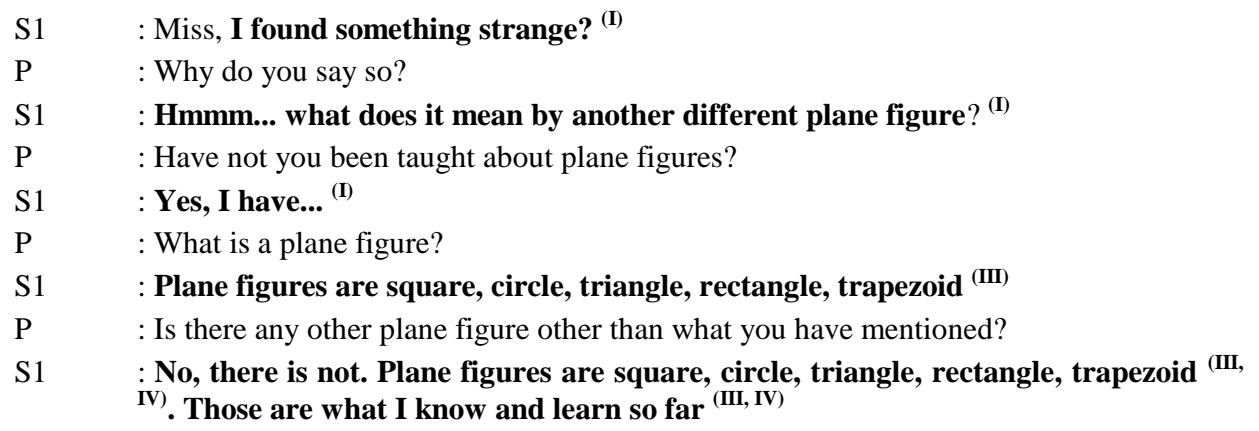

Based on the second interview, students were asked to give ideas on the answer sheet such as seen in Figure 4.

II Student reflected and used the square formulation to create
a square with the same area of trapezoid which is 64 units
III Student initially wanted to create a rhombus
with the area of 64 units
the third figure is triangle by arranging then conducted an improvement to create 2 unit
the same number as the trapezoid figure
and the two previous figures

Figure 4

The Results of the First Subject's Work in Responding to a Problem

In Figure 4 (I), the first figure made by the students was a square with the length of the sides was $4+4=8$ units and the area was 64 units. Figure 4 (II) shows that the student created a rhombus as the second figure. However, the student showed perplexity since the rhombus figure does not have the area of 64 units ${ }^{\text {(I) }}$. In Figure 4 (III), Student (S1) make the improvements on the second figure, namely (1) the student broke down one unit square into 2 triangular units, thus he is obtained two square units and four triangular units, (2) the student arranged two triangular units (each area of the square was 16 units) and 4 square units (each are from the triangle was 8 units) were to construct a hexagonal figure which has the area of 64 units. Figure 4 (IV) showed that the student created a triangle figure by arranging two unit squares and four unit triangles from the second figure. Figure 4 (IV, V, VI) showed that the student created triangle, rhombus, and new plane figures based on the arrangement of the unit square and unit triangle. The new plane figure showed that the student has overcome the problem and even invented a new finding that has never been taught at school.

Based on the results of the student's work (S1), the researcher asked the student to redescribe the results of the work. The researcher then conducted an interview with the 
student (S1) related to the perplexity causes experienced by the student in responding to the problem.

$\mathrm{P} \quad$ : How did you feel during the problem-solving?

S1 : At first, I felt confused because I have never got any question like this before $^{(\mathrm{I})}$

$\mathrm{P} \quad$ : What was the question like?

S1 : I was usually given a question which the length of each side has been known and I was asked to use a formula in determining the area (plane figure) ${ }^{(\mathrm{I}, \text { II })}$

$\mathrm{P} \quad$ : Do you think the fifth figure is a plane figure?

S1 : Yes, I do

P : Why?

S1 : The fifth figure has the same features as the first figure to the fourth figure which belongs to plane figure limited by straight lines or curves

\section{Second Subject:}

The second subject (S2) also showed a perplexity in responding to a problem since the subject experienced irregular problems. The perplexity emerged from the student's behavior who read the questions repeatedly and was silent most of the time. Based on this condition, the researcher asked the student (S2) to recognize deeper the difficulties or confusion experienced by the student. However, the researcher did not give any prompt questions directing to the answer solution.

$\mathrm{P} \quad$ : What kind of information can you find in this problem?

S2 : I can see there are nine lines in this trapezoid. The lengths of the parallel sides are 2 units and 4 units respectively, while the height is 3 units ${ }^{\text {(III) }}$

P : Why do you say so?

S2 : The number of dots on the upper side is 2 , while on the lower side is $4 .{ }^{\text {(III) }}$

$\mathrm{P} \quad$ : Oh I see.... what did you next?

S2 : I will make the other different plane figure which has the same area with this trapezoid.

P : What do you think a plane figure is?

S2 : Plan figures are triangle, square, rectangle, trapezoid ${ }^{\text {(III) }}$

$\mathrm{P} \quad$ : Can you define a plane figure in your own language?

S2 : Hmmm... Plan figures are triangle, square, rectangle, and trapezoid. ${ }^{\text {(III) }}$

P : Why do you say so?

S2 : I am usually taught like that. Plan figures are triangle, square, rectangle, trapezoid. ${ }^{(\mathrm{I}, \mathrm{III}, \mathrm{IV})}$

P : Oh ... What will you do next?

S2 : I will determine the area of this trapezoid.

Based on the video recording, student (S2) seemed confident in stating the argument, however, the student seemed to experience misconception on the experience thus far. 
The student misconception is shown in the delivery of the argument in resolving the problem. Student (S2) was asked to write down the argument on the answer sheet.

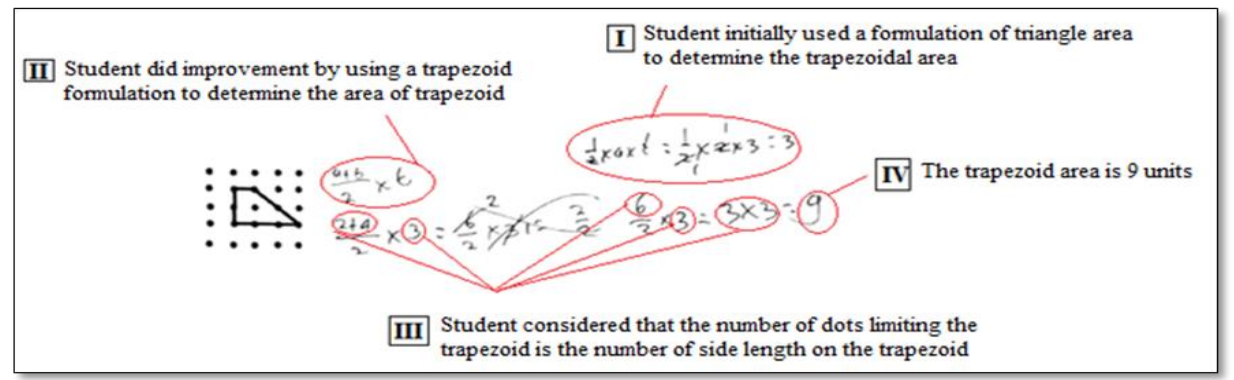

Figure 5

The Results of the Second Subject's Work in Performing Interview

Based on Figure 5 (I), the student initially used the formula of triangle area to determine the trapezoidal area ${ }^{\text {(III) }}$. Figure 5 (II) showed that student did improvement to determine the area of trapezoid using a trapezoid formula. In Figure 5 (III, IV), the student performed a calculation process to determine the trapezoid area by considering the number of dots as the length of trapezoid side thus the trapezoid area was 9 units (III). Student (S2) also gave an argument on the discovery of the trapezoid area to emphasize on the written results.

S2 : Hmmm....this trapezoid also has 9 dots limiting it.

$\mathrm{P} \quad$ : What does it mean?

S2 : The number of dots in this trapezoid is the same as the trapezoidal area by using the formula that is 9 .

$\mathrm{P} \quad$ : What will you do next?

S2 :I will make the other plane figures according to the number of dots in this trapezoid ${ }^{\text {(III) }}$

Based on the short interview, the student was asked to write down the argument on the answer sheet as can be seen in Figure 5.

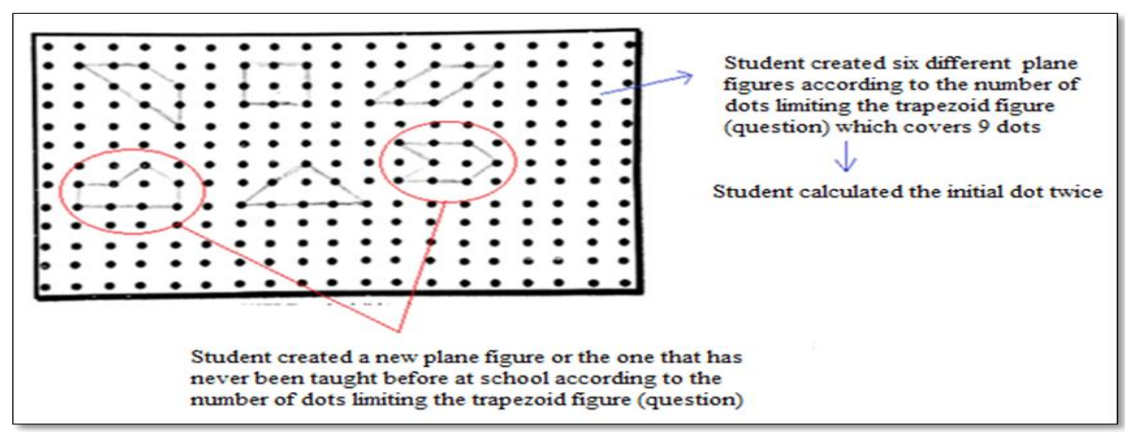

Figure 6

The Results of the Second Subject's Work in Responding to a Problem 
In Figure 6, the student made 6 plane figures according to the number of dots limiting the trapezoid figure (in the question) which covers 9 dots. The student calculated the initial dots twice because they think that the initial dot is as the final dot. From 6 plane figure in Figure 6, the student made two new plane figures or which have not been taught at school before.

\section{DISCUSSION}

Point (I) in the findings above showed that the first subject was unaccustomed to doing imagination and creation in solving non-routine problems on the learning activities. This condition is shown by the students' behavior who always asked related to the problem (question), uncertain or unsure on the problem and confused when asked to mention other plane figures thus needed a rather long time to make a decision in determining the problem-solving plan. This is in accordance with Nestadt et al. (2016) that the situation of uncertainty and unfamiliarity with a problem results in a person making a late decision. Uncommonness in imagination and creation in learning results in students being surprised because they experienced new things that he had never experienced. This condition is shown by the behavior of students who often make mistakes and repairs repeatedly to make a plane figure creatively (as in Figure 3. II-VI). This is in accordance with the opinion of Cheng (2016), namely the lack of creative learning that encourages imagination and creation of students in previous education provides novelty and surprise to students so that there are many obstacles in actualizing the creativity of students. Whereas, the second subject is accustomed to being introduced to some form of plane figure procedurally, without understanding the actual plane figure concept. Research conducted by Huang \& Witz (2011); Rahim \& Olson (1998) also showed that students are accustomed to focus on the introduction of regular and primitive plane figure shapes (such as square, triangle, rectangle, etc.). This is in line with the statement by Hong \& Chai (2017) that the practice of routine teaching developed from repeated teaching and high procedural skills in solving problems can provide a narrow understanding and cannot take the creativity of students in imagination and creation. The inability of students to control their habits against repetitive actions with routine procedures can inhibit the response and cognitive of students (Gillan, Robbins, Sahakian, Van Den Heuvel, \& Wingen, 2016). Based on the first sequence of argument from the first and second subjects, it can be concluded that the first and the second subjects experienced perplexity caused by the students' unfamiliarity in imagination and creation to solve the non-routine problems.

Based on Point (II) in the findings above, the first subject showed the existence of incompatibility between the problem-solving strategies that students have with the new problems that will be faced, where students first ask some questions about the information in routine problems that are always done but the information is not in the new problem. This is in accordance with the opinion of Hong \& Chai (2017),Wang, 2012), that problem-solving strategies chosen by students are always based on routine experiences and habits of students in solving the simple problems rather than solving the complex problems that they have previously performed, so that these conditions limit the students' construction in solving more complex/ non-routine problems. 
In the interview with the second subject in Point (II), the second subject applies the wrong problem-solving strategy that is the student uses the triangle area formula to determine the area of the trapezoid. This is because students often do not clearly determine what information will be needed to solve the problem so that students need to identify, prepare and define problems first in order to solve problems (Dostál, 2015). In this case, the knowledge that students use to get the right solution in a particular context that they often encounter resulting in a mistake when the knowledge is applied out of context (Batanero, Godino, Vallecillos, Green, \& Holmes, 2006). Based on the second sequence of argument from the first and second subjects, it can be concluded that the first and second subject experienced perplexity caused by incompatibility of the problems being solved and the use of the problem-solving strategy by the student.

Results of interviews with students in Point (III) shows that there is a misunderstanding of students (first and second subject) because of incompatibility student experience (this is evidenced by the student's statement which states the definition of flat building with some names of plane figure that they have known during class learning and considers the number of dots as side lengths), so students fail to understand and overcome new problems. This is in accordance with the opinion of (Yopp et al., 2011), that is, a very poor experience is not enough to overcome new problems and even lead to a misconception for students. The poor experience is also shown by the first subject, where the student forgot the trapezoidal area formula so that they experienced delayed in the problem-solving process. This is in accordance with the opinion of Cheng (2016) that the forgetfulness factor of what the student has learned or poor memory can hinder student learning in solving problems. Based on the third row of arguments from the first and second subjects, the perplexity of students is seen as students' misunderstandings in responding to problems because of incompatibility student experiences, or the existence of a forgotten factor.

The results of interviews with the subjects in Point (IV) showed that the first and second subjects failed to issue new ideas in responding to problems, because students did not want to change the mindset/design that was previously owned and did not want to develop self-confidence/creative efficacy to think of something else that was unusual. This is in accordance with the opinion of Lassig (2013) that the existence of a high ability of self-efficacy creativity can reduce the chance of "failure" or "error" of students to learn or obtain something new. Based on the fourth row of arguments, the first and second subjects experience perplexity caused by students' failure to issue new ideas/strategies. The perplexity over this problem is caused by the condition of cognitive disequilibrium of students (Yopp et al., 2011). The movement from the condition of disequilibrium to equilibrium is called the process of reflective thinking, so this condition of disequilibrium is the first step in the occurrence of reflective thinking (Rodgers, 2002).

The written work results from the first and second subjects indicate that they experience a perplexity to then lead to new findings, but after tracing from the students' arguments, the completion process of the first and second subjects is very different. The first subject can change the perplexity (disequilibrium) to equilibrium or the problem can be solved by the reflection process. Whereas, the second subject did not do the reflection process 
and remains in a state of disequilibrium, where the student makes another plan figure based on many points that limit the trapezoid (problem) and by chance, the plan figure made by the second subject is correct and even new. Based on a series of arguments from the two subjects, the results of the work of the second subject were correct but the results of the thinking were incorrect and still caused a lot of confusion; while the results of the work and thought of the first subject are appropriate to obtain new and true findings.

Based on the description above, this study provides several questions that have not been answered. These questions are intended for future research, namely (1) "how to change the perplexity (disequilibrium) of someone which can cause reflective thinking in students"; (2) how to change the perplexity (disequilibrium) of someone which can lead to new findings or creative thinking.

\section{CONCLUSION}

The conclusion in this study is the indicator from perplexity condition experienced by the students in responding to a problem namely students' unfamiliarity in imagination and creation on non-regular questions; incompatibility of problem-solving strategy owned by someone with the new problem-solving coming from; misunderstanding of students due to incompatibility students' experience, or the existence of a forgetfulness factor; and the failure in generating new ideas and strategies.

The knowledge on the causing indicators of perplexity experienced by the students in responding to a problem is very important to comprehend to give practical knowledge to the teachers and researchers, such as:

(1) For teachers who can make use of this knowledge as a reflection to construct a good learning strategy for students in responding to a problem; and

(2) For future researchers who can develop the knowledge on the indicator of perplexity on students as an initial process of the reflective thinking in responding to a mathematical problem.

\section{REFERENCES}

Azwar, S. (2017). Metode Penelitian Psikologi. Bandung: Pustaka Belajar.

Batanero, C., Godino, J. D., Vallecillos, A., Green, D. R., \& Holmes, P. (2006). Errors and difficulties in understanding elementary statistical concepts. International Journal of Mathematical Education in Science and Technology, 25(4), 527-547. https://doi.org/10.1080/0020739940250406

Bell, F. (1978). Teaching and learning mathematics (in secondary school). Lowa: W. M. C. Brown.

Cheng, V. M. Y. (2016). Understanding and enhancing personal transfer of creative learning. Thinking Skills and Creativity, 22, 58-73. https://doi.org/10.1016/j.tsc.2016.09.001

Creswell, J. W. (2015). Riset Pendidikan: Perencanaan, Pelaksanaan, dan Evaluasi Riset Kualitatif \& Kuantitatif Edisi Kelima. Yogyakarta: Pustaka Pelajar. 
Dostál, J. (2015). Theory of problem-solving. Procedia - Social and Behavioral Sciences, 174, 2798-2805. https://doi.org/10.1016/j.sbspro.2015.01.970

Eck, J. E. (2011). Assessing Responses to Problems: An Introductory Guide for Police Problem-Solvers. United States: Center for Problem-Oriented Policing, Inc.

Gillan, C. M., Robbins, T. W., Sahakian, B. J., Van Den Heuvel, O. A., \& Wingen, G. Van. (2016). The role of habit in compulsivity. European Neuropsychopharmacology, 26, 828-840. https://doi.org/10.1016/j.euroneuro.2015.12.033

Hallowell, D. A., Okamoto, Y., Romo, L. F., \& LaJoy, J. R. (2015). First-graders' spatial-mathematical reasoning about plane and solid shapes and their representations. ZDM Mathematics Education, 47(3), 363-375. https://doi.org/10.1007/s11858-0150664-9

Hong, H.-Y., \& Chai, C. S. (2017). Principle-based design: Development of adaptive mathematics teaching practices and beliefs in a knowledge building environment. Computers \& Education, 115, 38-55. https://doi.org/10.1016/j.compedu.2017.07.011

Huang, H.-M. E., \& Witz, K. G. (2011). Developing children's conceptual understanding of area measurement: A curriculum and teaching experiment. Learning and Instruction, 21(1), 1-13. https://doi.org/10.1016/j.learninstruc.2009.09.002

Huang, X., \& Lee, J. C. (2015). Disclosing Hong Kong teacher beliefs regarding creative teaching: Five different perspectives. Thinking Skills and Creativity, 15, 37-47. https://doi.org/10.1016/j.tsc.2014.11.003

Lassig, C. J. (2013). Approaches to creativity: How adolescents engage in the creative process. Thinking Skills and Creativity, 10, 3-12. https://doi.org/10.1016/j.tsc.2013.05.002

Muis, K. R., Chevrier, M., \& Singh, C. A. (2018). The Role of Epistemic Emotions in Personal Epistemology and Self-Regulated Learning. Educational Psychology, 1-20. https://doi.org/10.1080/00461520.2017.1421465

Nestadt, G., Kamath, V., Maher, B. S., Krasnow, J., Nestadt, P., Wang, Y., ... Samuels, J. (2016). Doubt and the decision-making process in obsessive-compulsive disorder. Medical Hypotheses, 96, 1-4. https://doi.org/10.1016/j.mehy.2016.09.010

Pagano, M., \& Roselle, L. (2009). Beyond reflection through an academic lens: Refraction and international experiential education. Frontiers: The Interdisciplinary Journal of Study Abroad, 18(II), 217-229. https://doi.org/Related link: URL: <http://www.frontiersjournal.com/upcomingissues.htm>

Papadopoulos, I. (2009). "Reinventing" Techniques for The Estimation Of The Area Of Irregular Plane Figures: From The Eighteenth Century To The Modern Classroom. International Journal of Science and Mathematics Education, 8(5), 869-890.

Posamentier, A. S., \& Krulik, S. (2009). problem-solving in Mathematics Grade 3 - 6: Powerful Strategies to Deepen Understanding. Thousand Oaks, California: Corwin, A 


\section{SAGE Company.}

Proulx, J. (2015). Behavior Mental mathematics with mathematical objects other than numbers: The case of operation on functions. Journal of Mathematical Behavior, 39, 156-176. https://doi.org/10.1016/j.jmathb.2015.07.001

Rahim, M. H., \& Olson, A. (1998). Qualitative Patterns in Plane Geometry. Journal of Mathematical Behavior, 17(3), 373-389.

Ricks, T. E. (2011). Process reflection during Japanese lesson study experiences by prospective secondary mathematics teachers. Journal of Mathematics Teacher Education, 14(4), 251-267. https://doi.org/10.1007/s10857-010-9155-7

Rodgers, C. (2002). Defining Reflection: Another Look at John Dewey and Reflective Thinking. Teachers College Record, 104(4), 842-866. https://doi.org/10.1111/14679620.00181

Skoumpourdi, C., \& Mpakopoulou, I. (2011). The Prints: A Picture Book for PreFormal Geometry. Early Childhood Education Journal, 39(3), 197-206. https://doi.org/10.1007/s10643-011-0454-0

Wang, A. Y. (2012). Exploring the relationship of creative thinking to reading and writing. Thinking Skills and Creativity, 7, 38-47. https://doi.org/10.1016/j.tsc.2011.09.001

Wu, M., \& Adams, R. (2006). Modelling Mathematics Problem Solving Item Responses Using a Multidimensional IRT Model. Mathematics Education Research Journal, 18(2), 93-113. https://doi.org/https://doi.org/10.1007/BF03217438

Yanik, H. B. (2014). Middle-school students' concept images of geometric translations. Journal of Mathematical Behavior, 36, 33-50. https://doi.org/10.1016/j.jmathb.2014.08.001

Yopp, D. A., Burroughs, E. A., \& Lindaman, B. J. (2011). The Journal of Mathematical Behavior Why it is important for in-service elementary mathematics teachers to understand the equality. $999 \ldots=1$. Journal of Mathematical Behavior, 30(4), 304318. https://doi.org/10.1016/j.jmathb.2011.07.007 